\title{
Extramedullary Tanycytic Ependymoma in a 12-Year-Old Boy
}

Sir,

Tanycytic Ependymomas (TE), rare WHO Grade II ependymomas, ${ }^{[1]}$ are primarily found in the intramedullary spinal cord ${ }^{[2,3]}$ of adults or within intraventricular regions of children's brains. ${ }^{[2-3]}$ TEs are rarely found on the extramedullary spinal cord ${ }^{[2,3]}$ and are more frequently seen in the cervical/cervicothoracic spinal cord than the thoracic, lumbar, or cauda equine ${ }^{[2,3]}$ A confident diagnoses of spinal cord TEs requires immunohistochemical (IHC) $\operatorname{stain}^{[2-4]}$ in conjunction with clinical presentation and light microscopy. The treatment is generally surgical, ${ }^{[2]}$ and postsurgical prognosis is good with tumor regrowth rarely seen. ${ }^{[2]}$

A 12-year-old boy presented with 3 months of intermittent low back pain that radiated bilaterally to his upper thighs. His neurological examination was nonfocal and uneventful except for positive bilateral straight leg raising test. A lumbar spine magnetic resonance imaging (MRI) revealed an intradural, extramedullary mass at L1-L3 region, inferior to the conus medullaris and inside the cauda equina. Homogeneous enhancement and mass effect were also observed on the cauda equina roots [Figure 1a and $\mathrm{b}$ ]. The patient underwent L1-L2-L3 osteoplastic laminectomies for gross total resection (GTR). Intraoperative visualization showed the tumor within the subarachnoid space and attached to the filum terminale and a few nerve roots [Figure 2a]. Intraoperative neurophysiological monitoring was used to ensure safe detachment of nerves from tumor. The tumor was removed in one piece [Figure $2 b$ ] with frozen 


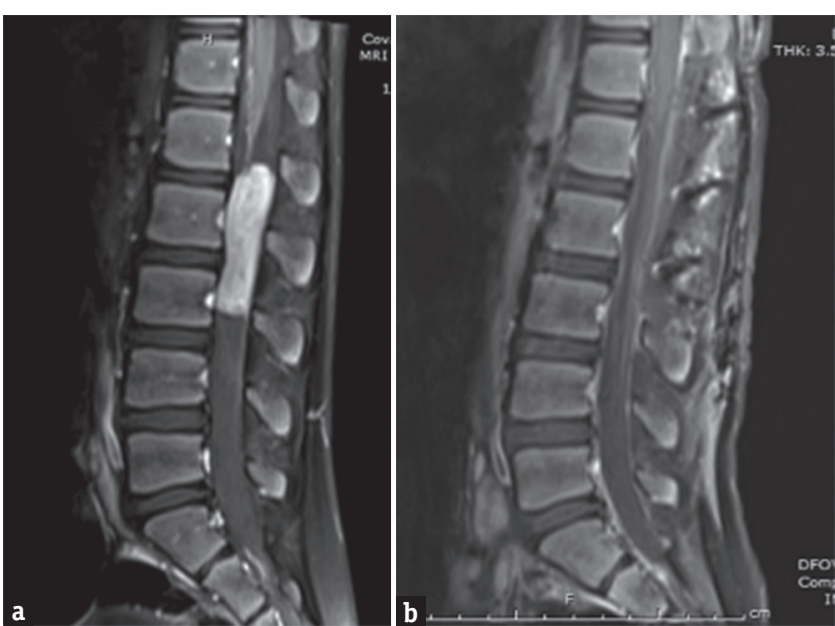

Figure 1: Preoperative (a) and postoperative (b) sagittal post contrast magnetic resonance imagings

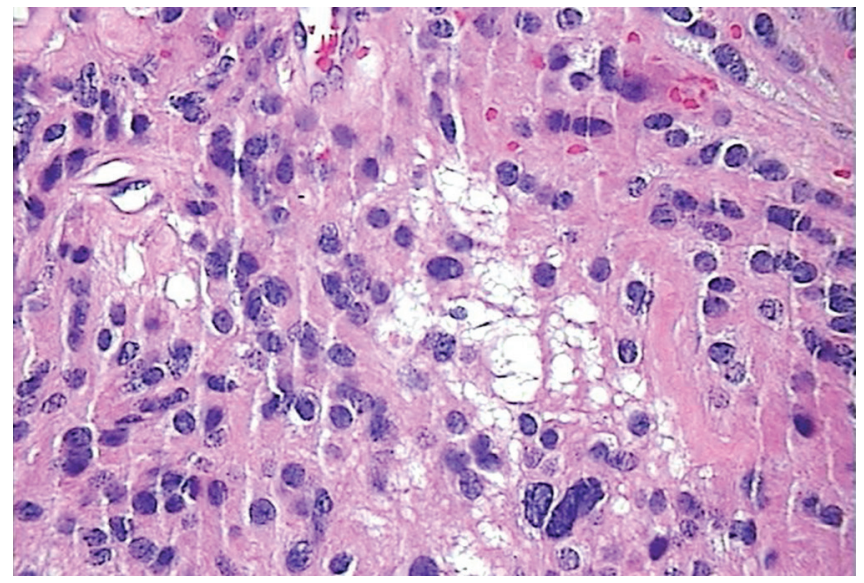

Figure 3: Vacuolated Cells on Hematoxylin and Eosin Stain at 400x

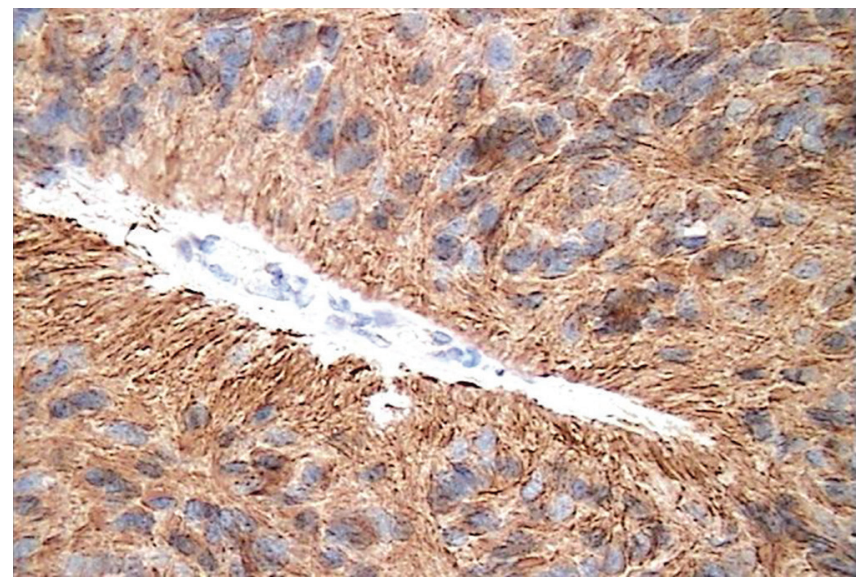

Figure 5: Glial Fibrillary Acidic Protein Stain on Immunohistochemical Stain at $400 \mathrm{x}$

sections sent for biopsy. Filum terminale could not be visualized clearly, and no nerve roots were sacrificed.

Light microscopy of $\mathrm{H}$ and $\mathrm{E}$ stained sections demonstrated spindle cell neoplasms of lowtomoderate cellularity with vacuolated cells [Figure 3] and

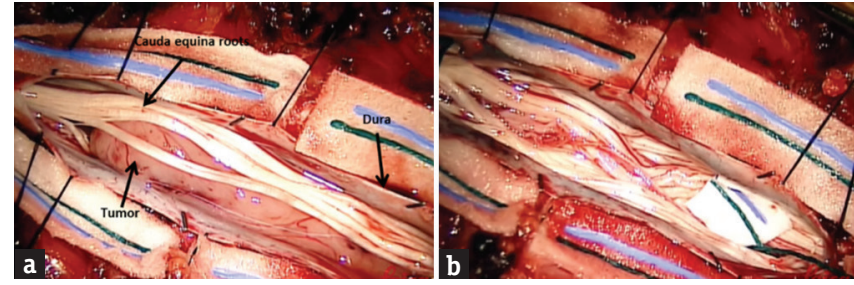

Figure 2: Intraoperative pictures showing before (a) and after (b) gross total resection

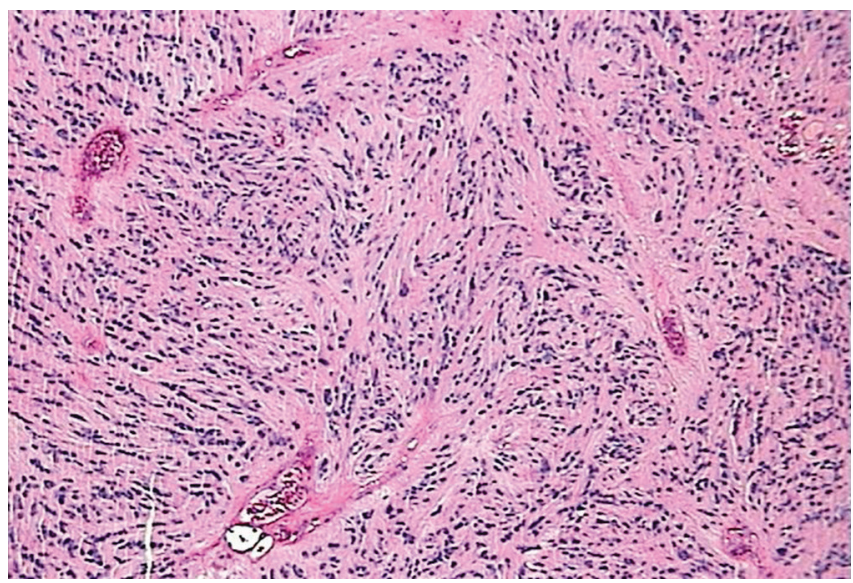

Figure 4: Inconspicuous Pseudorosettes on Hematoxylin and Eosin Stain at $100 \mathrm{x}$

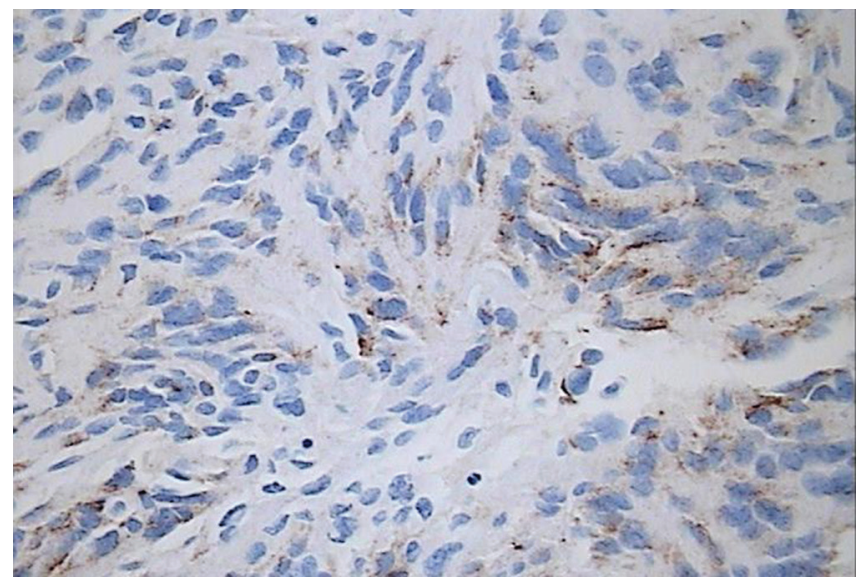

Figure 6: Epithelial Membrane Antigen Stain on Immunohistochemical Stain at $200 x$

illdefined perivascular pseudorosettes [Figure 4] on light microscopy. High-grade features such as increased mitoses or necrosis were not observed. IHC stains were positive for glial fibrillary acidic protein [Figure 5] and dot-like positivity for epithelial membrane antigen [Figure 6].

Postoperative MRIs confirmed GTR with no remaining lesions or neurological deficits [Figure 1b]. After consulting with pediatric neurooncology and discussing with parents, the boy received prophylactic proton therapy to the tumor bed. A 2 years' follow-up showed neither recurrence of the tumor nor neurological deficits. 
Rare features of the TE were encountered. TEs are not generally seen in the pediatric population and most incidences are reported in adults - mean age between 40 and 42-year-old. ${ }^{[2,3]}$ If present in children, TEs are more likely to be found in the brain's intraventricular regions ${ }^{[2]}$ or the intramedullary cervico/cervicothoracic region ${ }^{[2,3]}$ of the spinal cord. In contrast to the mean age and location, this patient was 12-year-old, and his TE was in the extramedullary cauda equina.Only three other cases of a pediatric spinal TEs have been reported, with one involving an extramedullary $\mathrm{TE}$ in the cauda equina of a 10 -year-old girl. ${ }^{[1,4,5]}$

\section{Declaration of patient consent}

The authors certify that they have obtained all appropriate patient consent forms. In the form the patient(s) has/have given his/her/their consent for his/ her/their images and other clinical information to be reported in the journal. The patients understand that their names and initials will not be published and due efforts will be made to conceal their identity, but anonymity cannot be guaranteed.

\section{Financial support and sponsorship}

Nil.

\section{Conflicts of interest}

There are no conflicts of interest.

\section{Preston D'Souza, William E. Martin, Surender Bodhireddy', Muhittin Belirgen}

Department of Pediatrics, Division of Pediatric Neurosurgery, School of Medicine, Texas Tech University Health Sciences Center, 'Department of Pathology, School of Medicine, Texas Tech University Health Sciences Center, Lubbock, TX, USA
Address for correspondence: Dr. Muhittin Belirgen, $36014^{\text {th }}$ Street, Lubbok, TX 79415, USA. E-mail: Muhittin.belirgen@ttuhsc.edu

\section{REFERENCES}

1. Friede RL, Pollak A. The cytogenetic basis for classifying ependymomas. J Neuropathol Exp Neurol 1978;37:103-18.

2. Tao X, Hou Z, Hao S, Zhang Q, Wu Z, Zhang J, et al. The clinical features and surgical outcomes of spinal cord tanycytic ependymomas: A report of 40 cases. World Neurosurg 2017; 106:60-73.

3. Tomek M, Jayajothi A, Brandner S, Jaunmuktane Z, Lee $\mathrm{CH}$, Davagnanam I, et al. Imaging features of spinal tanycytic ependymoma. Neuroradiol J 2016;29:61-5.

4. Mohindra S, Bal A, Singla N. Pediatric tanycytic ependymoma of the cauda equina: Case report and review of the literature. J Child Neurol 2008;23:451-4.

5. Ueki K, Sasaki T, Ishida T, Kirino T. Spinal tanycytic ependymoma associated with neurofibromatosis type 2 - Case report. Neurol Med Chir (Tokyo) 2001;41:513-6.

This is an open access journal, and articles are distributed under the terms of the Creative Commons Attribution-NonCommercial-ShareAlike 4.0 License, which allows others to remix, tweak, and build upon the work non-commercially, as long as appropriate credit is given and the new creations are licensed under the identical terms.

\begin{tabular}{|l|l|}
\hline \multicolumn{2}{|c|}{ Access this article online } \\
\hline Quick Response Code: & Website: \\
\hline
\end{tabular}

How to cite this article: D'Souza P, Martin WE, Bodhireddy S, Belirgen M. Extramedullary tanycytic ependymoma in a 12 -year-old boy. J Neurosci Rural Pract 2019;10:381-3.

C 2019 Journal of Neurosciences in Rural Practice | Published by Wolters Kluwer - Medknow 